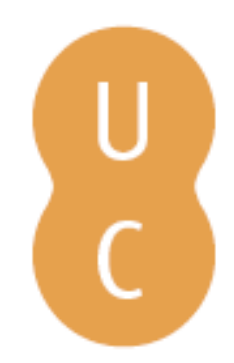

\title{
pommalina
}

\section{Plantas aquáticas e florestas ribeirinhas}

Autor(es): $\quad$ Aguiar, Francisca C.; Espírito-Santo, M. Dalila; Ferreira, M. Teresa

Publicado por: Imprensa da Universidade de Coimbra

URL

persistente: URI:http://hdl.handle.net/10316.2/45883

DOI: $\quad$ DOl:https://doi.org/10.14195/978-989-26-1624-7_6

Accessed : $\quad$ 26-Apr-2023 00:28:37

A navegação consulta e descarregamento dos títulos inseridos nas Bibliotecas Digitais UC Digitalis, UC Pombalina e UC Impactum, pressupõem a aceitação plena e sem reservas dos Termos e Condições de Uso destas Bibliotecas Digitais, disponíveis em https://digitalis.uc.pt/pt-pt/termos.

Conforme exposto nos referidos Termos e Condições de Uso, o descarregamento de títulos de acesso restrito requer uma licença válida de autorização devendo o utilizador aceder ao(s) documento(s) a partir de um endereço de IP da instituição detentora da supramencionada licença.

Ao utilizador é apenas permitido o descarregamento para uso pessoal, pelo que o emprego do(s) título(s) descarregado(s) para outro fim, designadamente comercial, carece de autorização do respetivo autor ou editor da obra.

Na medida em que todas as obras da UC Digitalis se encontram protegidas pelo Código do Direito de Autor e Direitos Conexos e demais legislação aplicável, toda a cópia, parcial ou total, deste documento, nos casos em que é legalmente admitida, deverá conter ou fazer-se acompanhar por este aviso.

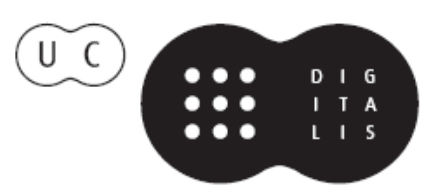


MARIA JOÃO FEIO

VERÓNICA FERREIRA

(EDS.)

\section{IMPRENSA DA \\ UNIVERSIDADE \\ DE COIMBRA \\ COIMBRA \\ UNIVERSITY \\ PRESS}

\section{RIOS DE PORTUGAL COMUNIDADES, PROCESSOS E ALTERAÇÕES}




\section{CA P Í T ULO 6 \\ PLANTAS AQUÁTICAS E \\ FL O RESTAS RI B E I RINHAS}

Francisca C. Aguiar'1, M. Dalila Espírito-Santo ${ }^{2}$ \& M. Teresa Ferreira ${ }^{3}$

${ }^{1}$ Centro de Estudos Florestais, Instituto Superior de Agronomia, Universidade de Lisboa, Portugal, fraguiar@isa.ulisboa.pt

${ }^{2}$ Centro de Investigação em Agronomia, Alimentos, Ambiente e Paisagem, Instituto Superior de Agronomia, Universidade de Lisboa, Portugal, dalilaesanto@isa.ulisboa.pt

${ }^{3}$ Centro de Estudos Florestais, Instituto Superior de Agronomia, Universidade de Lisboa, Portugal, terferreira@isa.ulisboa.pt

Resumo: Os sistemas fluviais em Portugal destacam-se na paisagem como corredores verdes e azuis, que penetram no complexo mosaico de usos agrícola, florestal, agro-florestal e urbano. A flora associada a estes sistemas, vulgarmente designada por flora aquática e ribeirinha, estrutura-se em comunidades específicas de acordo com as características ambientais do meio aquático e dos ecossistemas envolventes. Está ainda dependente das pressões humanas decorrentes do uso dos recursos hídricos. A importância destas comunidades não se esgota na riqueza florística per si, ou na estética visual conseguida pela presença de plantas aquáticas ou pela diversidade de gradientes cromáticos entre os bosques ribeirinhos e as áreas envolventes. Quer as comunidades herbáceas, quer as lenhosas, desempenham múltiplas funções nos ecossistemas fluviais, estabelecendo inter-relações com outras comunidades 
aquáticas e terrestres e proporcionando variados serviços dos ecossistemas. Em Portugal, a par de estudos de flora, sistemática, fitossociologia e ecologia, estas comunidades têm suscitado interesse dos responsáveis pela gestão e conservação de sistemas fluviais, e são alvo de importantes diretivas comunitárias. Atualmente, devido à crescente pressão sobre o uso dos sistemas fluviais, como é o caso da implementação de barragens para produção de energia hidroelétrica, ou da captação de água para irrigação e usos industriais e urbanos, torna-se premente o conhecimento dos fatores influentes das comunidades para proteção destas formações vegetais, bem como da flora específica que está intimamente associada a determinadas condições habitacionais. Este capítulo pretende resumir as principais conquistas no conhecimento da flora e vegetação aquática e das florestas ribeirinhas em Portugal, bem como os desafios futuros de investigação, conservação e gestão destes ecossistemas.

Palavras-chave: conservação, flora aquática, floresta ribeirinha, gestão, rios, vegetação

\section{Flora e vegetação em rios portugueses}

A vegetação aquática e ribeirinha constitui um elemento funcional e estruturante dos sistemas fluviais. A par do seu papel na produção de oxigénio e biomassa, nos ciclos biogeoquímicos de nutrientes, na regulação biofísica da temperatura da água, vento e luz, e ainda como refúgio, alimentação e habitat para outros organismos, é-lhe atribuída a função de "engenheiros dos ecossistemas", em reconhecimento da sua ação de suporte, proteção contra a erosão e modificação biogeomorfológica. Em particular, as florestas ribeirinhas são corredores 
ecológicos que albergam elevada biodiversidade, constituindo um importante filtro biológico para poluentes e nutrientes provenientes das zonas agrícolas contíguas, para além de poderem proporcionar retorno económico pela produção de bens (p.ex., madeira, plantas aromáticas ou com propriedades medicinais), pela proteção contra cheias e oferecer outros valores menos tangíveis, como os cénico-paisagísticos, recreativos, patrimoniais e culturais. No entanto, estes bens e serviços da vegetação aquática e ribeirinha nem sempre são valorizados pelas populações e responsáveis locais, nem pelos visitantes e pelos proprietários das terras confinantes.

Estas formações arbóreo-arbustivas ribeirinhas são muitas vezes sujeitas a cortes extensos para permitir o acesso aos cursos de água ou para aumentar a área agrícola ou florestal (p.ex., eucaliptais). A remoção indiscriminada da vegetação aquática para melhoria do escoamento é também uma prática comum nos rios portugueses. Por outro lado, estes sistemas podem ser invadidos por espécies de plantas exóticas, introduzidas de forma voluntária para supostamente melhorar a qualidade da paisagem (caso da acácia e do jacinto-aquático) ou a sustentação das margens (caso da cana), revelando um generalizado desconhecimento dos efeitos negativos destas práticas. Estes ecossistemas estão ainda sujeitos a degradação devido a drenagens, pastoreio, ao uso dos recursos hídricos para irrigação, consumo urbano e produção de energia hidroelétrica e são vulneráveis aos efeitos das alterações climáticas e fogos. Nos vales de cheia, a conexão das florestas ribeirinhas com os ecossistemas adjacentes é muitas vezes interrompida pela impermeabilização dos solos (estradas, áreas industriais e urbanas).

A monitorização e gestão integrada destes ecossistemas são de particular importância para a conservação. Portugal caracteriza-se por uma enorme diversidade de solos, geomorfologia, relevo, geologia, clima e usos da terra, que determinam a existência de tipos de rios distintos, promovendo comunidades com diferentes 
características e com composição florística adaptada a estes fatores biofísicos. Enquanto no sul do país é frequente encontrar estreitos corredores verdes que serpenteiam a árida paisagem mediterrânica, no noroeste, as florestas ribeirinhas, embora de largura reduzida, podem confundir-se na paisagem com as florestas de caducifólias contíguas, como os carvalhais. Por sua vez, os rios de montanha suportam, entre os blocos rochosos das margens, formações de estrutura vertical simples e dominadas por arbustos ${ }^{1}$. Esta grande diversidade de galerias ribeirinhas e o desconhecimento do seu estado de conservação assegurou um grande interesse pelo seu estudo nas últimas décadas, pelo que tem sido abordado em várias áreas do conhecimento, como a biogeografia, ecologia, conservação, requalificação, monitorização e gestão. Por sua vez, estudos de flora e vegetação aquática em Portugal remontam ao final do século XIX, com importantes estudos taxonómicos e biogeográficos, passando a ecologia fluvial a merecer um lugar de destaque sobretudo a partir da segunda metade do século XX. Mais recentemente, surgiram estudos aplicados de conservação e mapeamento de habitats, monitorização, requalificação e gestão sustentável, impulsionados

por importante legislação comunitária, como a Diretiva Habitats ${ }^{2}$ e a Diretiva Quadro da Água (DQA) ${ }^{3}$.

\section{Flora e comunidades aquáticas}

A vegetação do leito dos rios, vulgarmente designada por vegetação aquática é de facto composta por várias comunidades que se posicionam consoante a profundidade e tipo de substrato. Em termos gerais, podem distinguir-se comunidades de espécies aquáticas em sentido estrito, também designadas de hidrófitos, e comunidades de espécies que toleram a submersão temporária, designadas por vegetação emergente ou helófitos. Enquanto as 
primeiras são dominadas por tecidos fotossinteticamente ativos e dependem da transparência da água e das condições dos leitos, as segundas apresentam uma proporção importante de tecidos de suporte e o seu estabelecimento está mais associado ao regime de caudais e ao stress hidráulico ${ }^{4,5}$.

Encontramos comunidades de plantas aquáticas diversas consoante o conteúdo em nutrientes e o regime hidrológico. Em Portugal, em águas remansadas e profundas ocorrem hidrófitos enraizados como os nenúfares (Nymphaea alba), os golfões-amarelos (Nuphar lutea) e os miriófilos nativos (caso do Myryiophyllum verticillatum). Em locais com conteúdos médios de nutrientes orgânicos - águas mesotróficas - ocorrem comunidades formadas por hidrófitos flutuantes como as lentilhas-de-água-menores (Lemna minor) ou os ranúnculos (Ranunculus spp.) (Figura 6.1a), enquanto em águas com baixo conteúdo em nutrientes - águas oligotróficas - e permanentes as espécies aquáticas flutuantes são substituídas por comunidades enraizadas, como é o caso de algumas espécies dos géneros Potamogeton, Callitriche e Myriophyllum (Figura 6.1b).

Os sistemas fluviais albergam também comunidades exuberantes de briófitos aquáticos, que são vulgarmente designados por musgos aquáticos, como é o caso do Rhynchostegium riparioides e das espécies do género Fontinalis, e incluem algumas espécies vulneráveis e endémicas $^{6}$ (Figura 6.1c). No entanto, das mais de 150 espécies de musgos e hepáticas recenseados nos leitos dos rios de Portugal continental pouco perturbados, a proporção de briófitos aquáticos é apenas de $18 \%$ do total ${ }^{7}$. Para além destas plantas não vasculares, também é possível encontrar hidrófitos submersos como a erva-do-peixe-dourado (Ceratophyllum demersum) característica de águas permanentes de corrente lenta. Nas zonas inundadas de baixa profundidade e nas margens surgem comunidades de espécies emergentes, das quais são emblemáticas as comunidades formadas por helófitos de grandes dimensões e inflorescências atraentes, como as formadas por tabúas (Typha spp.), 
bunho (Scirpus lacustris) e os caniçais (Phragmites australis), bem como as constituídas por lírio-amarelo (Iris pseudacorus) e espadana-de-água (Sparganium erectum). Em cursos de água torrenciais, é comum encontrar o embude (Oenanthe crocata), espécie tóxica, muito comum em todo o país (Figura 6.1d). Há ainda a assinalar um elenco florístico muito vasto de pequenos helófitos, onde se inserem as junças, juncos e os Carex, sendo de destacar a espécie endémica Carex elata subsp. reuteriana, abundante em cursos de água rochosos, de regime permanente e bem conservados (Figura 6.1e).
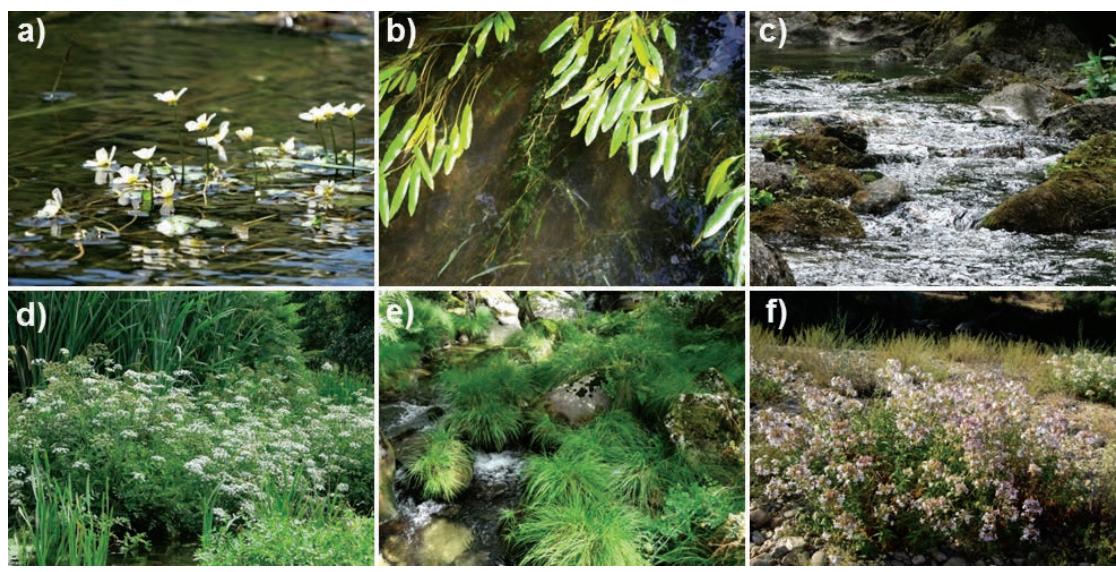

Figura 6.1. Exemplos de espécies aquáticas e emergentes comuns nos sistemas fluviais Portugueses: a) Ranunculus spp.; b) Potamogeton spp.; c) musgos aquáticos; d) embude Oenanthe crocata ; e) Carex elata subsp. reuteriana; f) erva-do-sabão Saponaria officinalis. Fotografias:

Francisca Aguiar.

O elenco de espécies encontrado no corredor fluvial (leito e zona ripária) representa cerca de $30 \%$ da flora vascular portuguesa, não obstante metade serem espécies de carácter terrestre que também aí ocorrem, uma vez que é a zona do vale com maior humidade. Nos substratos húmidos das margens ou sob o coberto das árvores e arbustos ribeirinhos, é frequente a ocorrência de plantas designadas genericamente por higrófitos, que incluem, por exemplo, 
a erva-do-sabão (Saponaria officinalis) (Figura 6.1f), a verbena (Verbena officinalis) e a labaça-comum (Rumex conglomeratus). Mais de 900 espécies podem ser encontradas no corredor fluvial mas apenas cerca de 180 se podem considerar aquáticas ou dependentes de alagamento do solo (plantas emergentes) (Figura 6.2).

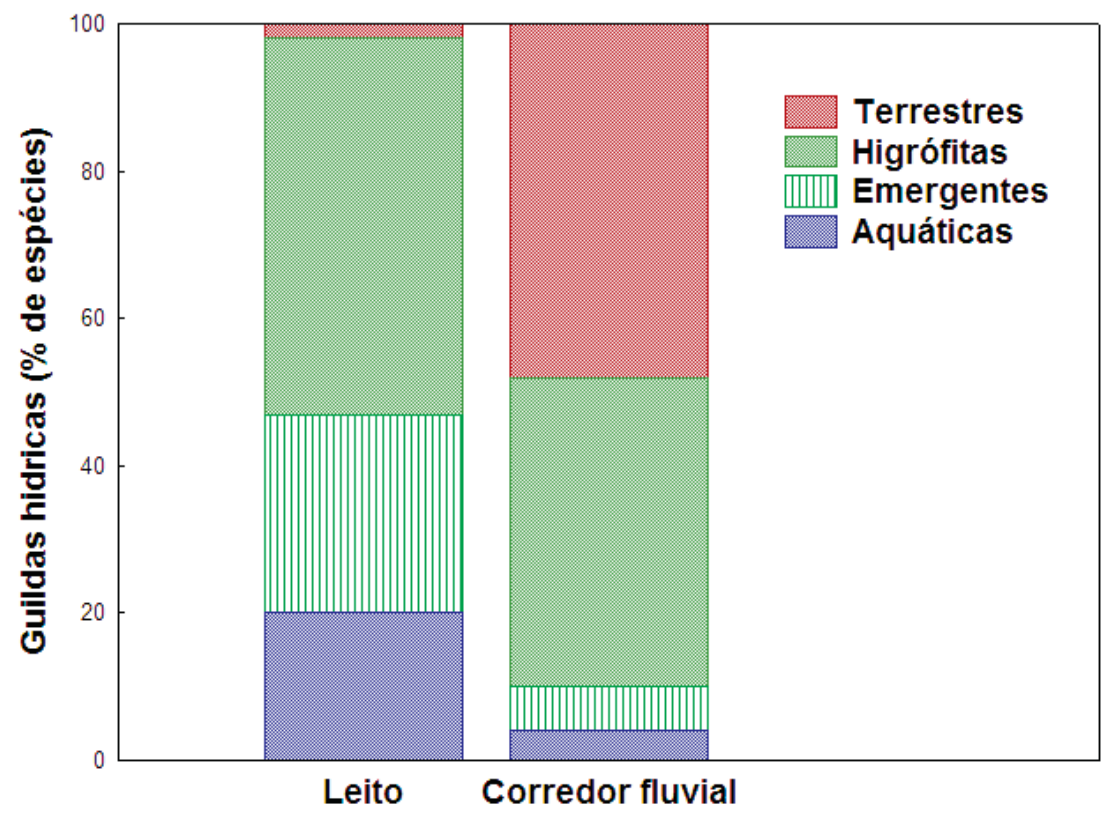

Figura 6.2. Proporção de espécies com diferentes graus de associação ao meio aquático em Portugal (dados de campo recolhidos em cerca de 400 locais, de todos os tipos de rios no âmbito da implementação da DQA) no leito e no corredor fluvial.

\section{Florestas ribeirinhas}

As florestas ribeirinhas (ripícolas ou ripárias) também designadas por bosques ribeirinhos ou galerias ribeirinhas são componentes fundamentais da paisagem fluvial. Estes corredores de vegetação situados na interface entre o meio aquático e o meio terrestre (zona ripária 
ou ripícola), desenvolvem-se num dos mais diversos, complexos e dinâmicos habitats existentes e possuem uma identidade florística e estrutural amplamente distinta destes ecossistemas contíguos ${ }^{8-10}$.

As galerias ribeirinhas são formadas por uma variedade de árvores que não é aleatória. Vemos muitas vezes os freixos (Fraxinus angustifolia) ou os choupos (Populus spp.) a ladear as estradas em zonas de várzea, mas nunca vemos amieiros (Alnus glutinosa) ou salgueiros (Salix spp.) com essa localização a menos que a estrada passe muito perto da linha de água. Na verdade, a água disponível manifestada pelo regime do caudal, permanente ou temporário, e pela largura do seu leito, em vale mais ou menos apertado ou em lezírias aplanadas, é determinante na definição da galeria ribeirinha que aí vai ocorrer. Ou seja, os diferentes regimes fluviais e a morfologia dos fundos de vale dão origem a diferentes tipos de bosques/galerias ribeirinhas. O gradiente originado por esses fatores origina séries de vegetação diferentes, cada uma delas constituída pelas comunidades que compõe, em cada ponto, a sucessão ecológica. Ao conjunto das séries que se instalam no fundo de um determinado vale sujeito à dinâmica fluvial atual dá-se o nome de geossérie ripícola. Assim, a vegetação ribeirinha distribui-se ao longo do perfil longitudinal dos rios, em resultado da variabilidade geográfica (p.ex., altitude, declive, topografia) e local (p.ex., largura do rio). Em Portugal continental, esta variabilidade geomorfológica e climática dita padrões de composição florística, estrutural e funcional distintos consoante o tipo de rio. No entanto, é comum terem largura reduzida, formando faixas ao longo dos rios e albergarem sob coberto um elenco florístico extenso. As galerias ribeirinhas apresentam uma zonagem transversal resultante da interação entre a autoecologia das espécies, o substrato e declive da margem e o regime de caudais, em que os indivíduos mais jovens e as espécies mais dependentes da água se localizam perto do canal e os mais velhos, de raízes mais profundas ou associados a ciclos 
de submersão extensos, se localizam mais longe do canal (Figura 6.3). A vegetação perto do canal é destruída em parte anualmente pelas cheias de inverno mas apresenta uma recuperação rápida (i.e., elevada resiliência) e está sempre ligada ao meio aquático, e a vegetação mais afastada é estável em composição, mais madura e estruturada, com sub-bosque e complexidade vegetal notável, e por isso mais resistente a flutuações na hidrologia ${ }^{10}$. Porém, quando o ambiente mediterrâneo é extremo, os ciclos de seca e cheias tornam a faixa de vegetação ripária mais estreita e menos estruturada, mais envelhecida e de recrutamento difícil.
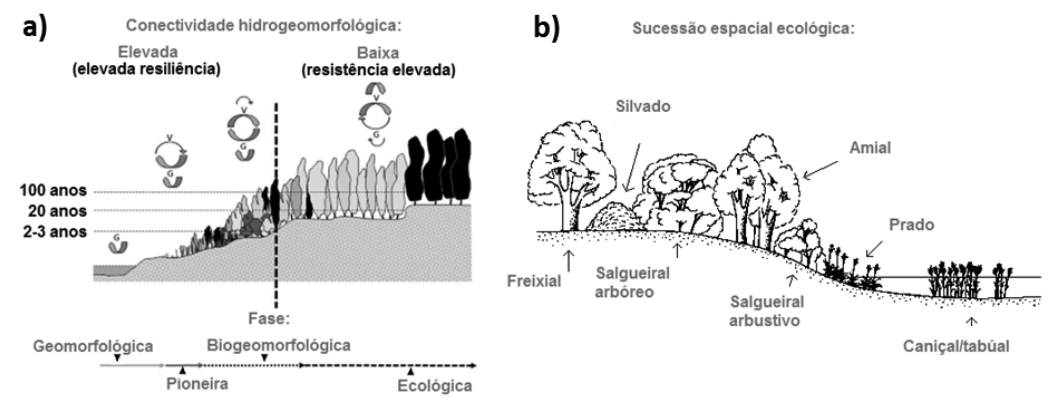

Figura 6.3. a) Sucessão biogeomórfica fluvial (FBS) da vegetação lenhosa nos bosquetes ripários ditada pelo perfil transversal do rio e pelo regime de caudais; $V=$ vegetação; $G=$ geomorfologia, adaptado de Corenblit et $a{ }^{11}$ ), b) sucessão típica em cursos médios e de regime permanente, adaptado de Aguiar et al. $\left.{ }^{14}\right)$.

A flora lenhosa ribeirinha que ocorre nos nossos cursos de água conta com mais de uma centena de espécies sendo, no entanto, apenas cerca de vinte as frequentes e dominantes na paisagem fluvial. Em linhas de água de carácter permanente, ou torrencial, mas com pouca estiagem, estabelecem-se bosques caducifólios, como os freixiais, amiais, olmedos e vidoais, estes últimos em locais de maior longitude e/ou altitude. Dominam nestas formações, respetivamente, o freixo, o amieiro, os ulmeiros (Ulmus spp.) e 
a bétula (Betula celtiberica). São também frequentes salgueirais arbóreo-arbustivos, constituídos por várias espécies de salgueiros, como a borrazeira-negra (Salix atrocinerea), a borrazeira-branca (Salix salviffolia), o salgueiro-branco (Salix alba), entre outros (Figura 6.4). Estes bosques fazem-se acompanhar por espécies arbóreas e arbustivas como o sanguinho-de-água (Frangula alnus), o pilriteiro (Crataegus monogyna), o sabugueiro (Sambucus nigra), a aveleira-brava (Corylus avellana), o lodão (Celtis australis), os choupos (Populus spp.), as urzes (Erica spp.), o azereiro (Prunus lusitanica) e o carvalho-roble (Quercus robur). Merece ainda destacar as trepadeiras lenhosas, nas quais se incluem várias espécies de silvas (Rubus spp.), as heras (Hedera spp.) e a videira-selvagem (Vitis vinifera subsp. sylvestris) bem como trepadeiras herbáceas como as madressilvas (Lonicera spp.) ou a doce-amarga (Solanum dulcamara). As comunidades ripícolas típicas de cursos de água temporários ou de regime torrencial e sujeitos a maior estiagem (sobretudo Alentejo e Algarve) são compostas por comunidades de espécies perenifólias (i.e., espécies que mantêm as folhas durante todo o ano), como o loendro (Nerium oleander) e as tamargueiras (sobretudo Tamarix africana), ou esclerófilas (i.e., espécies com folhas endurecidas e protegidas por cutículas), como o tamujo (Flueggea tinctoria; arbusto endémico da Península Ibérica). São também frequentes os salgueirais arbustivos, comunidades pioneiras adaptadas a flutuações do nível de água que ocorrem sobretudo em solos aluvionares, geralmente siliciosos (Figura 6.4).

Embora, a identidade e visibilidade destes bosques ribeirinhos esteja ligada às espécies lenhosas, sobretudo árvores e arbustos, as espécies herbáceas que coabitam sob o coberto arbóreo-arbustivo ou junto às margens menos ensombradas são parte integrante destas formações e têm uma enorme importância do ponto de vista ecológico e funcional. Deste vasto universo de espécies, podemos referir, como exemplos frequentes, a salgueirinha (Lythrum salicaria), o 
morroio-de-água (Lycopus europaeus), o poejo (Mentha pulegium), o mentrastro (Mentha suaveolens), os miósotis (Myosotis spp.), a pimenta-de-água (Polygonum hydropiper), as junças (Cyperus spp.) e os juncos (Juncus spp.).
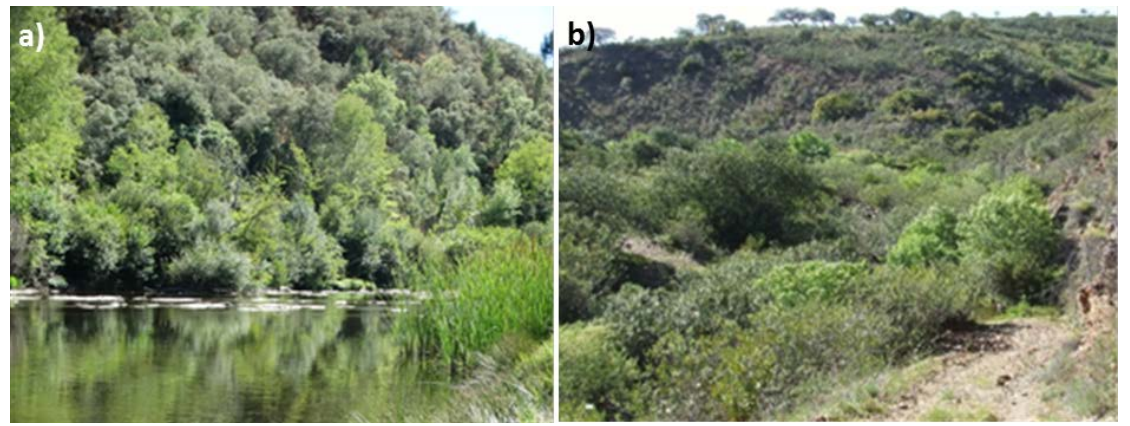

Figura 6.4. a) Bosque ribeirinho caducifólio, amial no rio Rabaçal; b) bosque ribeirinho Mediterrâneo, loendral na Ribeira de Alportel). Fotografias: Francisca Aguiar e Teresa Ferreira.

\section{Espécies exóticas e invasoras}

Os rios e as zonas ribeirinhas são ambientes extremamente vulneráveis à colonização por espécies exóticas. Estes ecossistemas dispõem de condições privilegiadas à dispersão de sementes e propágulos a grandes distâncias e a existência de água e nutrientes proporcionam um ambiente favorável para a generalidade das espécies exóticas. Foram encontradas mais de uma centena de espécies exóticas nas margens e no leito dos nossos rios, no entanto, menos de $10 \%$ são aquáticas ou emergentes, sendo as restantes terrestres ${ }^{12}$. Comparativamente, o número de espécies endémicas (lusitanas, ibéricas e europeias) é menor, mas em proporção semelhante em espécies aquáticas, emergentes e higrófitas (Figura 6.5). De uma forma geral, mesmo em rios portugueses muito pouco alterados por atividades humanas é possível encontrar espécies exóticas, no 
entanto, a cobertura destas é proporcionalmente superior em rios degradados, sendo os casos mais visíveis a substituição de muitas galerias ribeirinhas arbóreas por cana (Arundo donax) e de herbáceas de margem por graminhão (Paspalum distichum), de origem tropical.

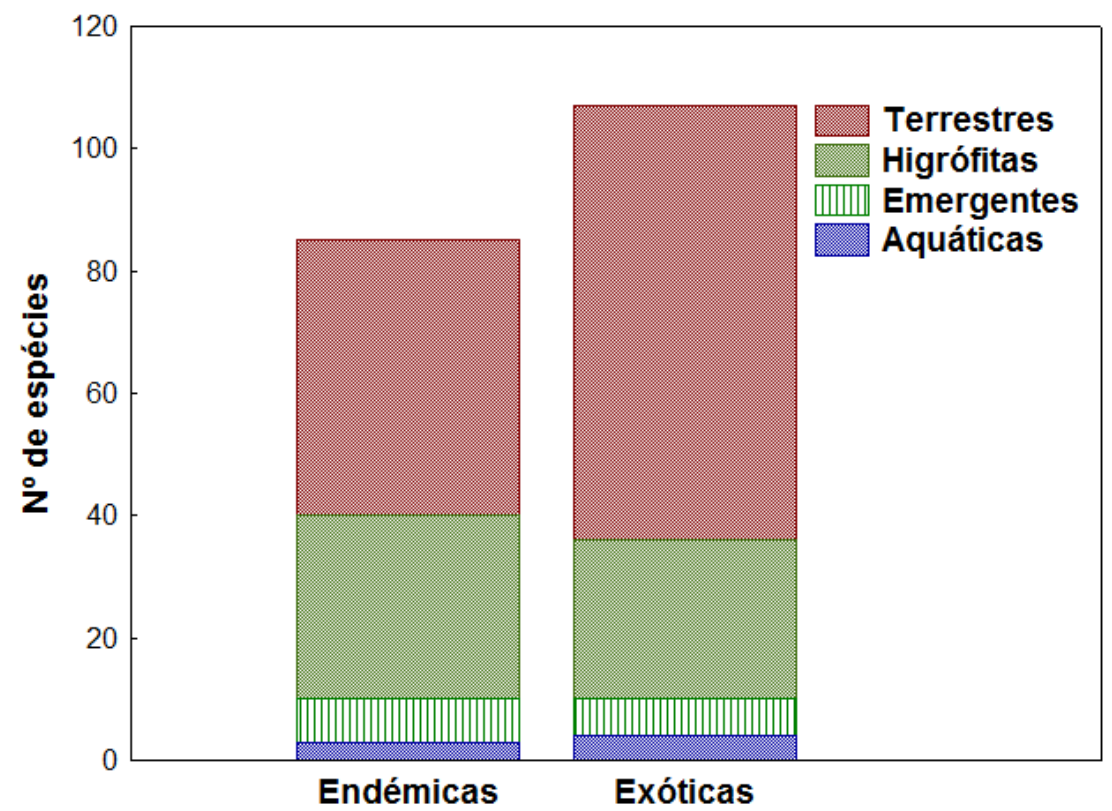

Figura 6.5. Proporção de espécies endémicas e exóticas em rios portugueses em cerca de 400 locais amostrados no âmbito da implementação da Diretiva Quadro da Água.

Menos de vinte espécies exóticas poderão considerar-se invasoras, ou seja espécies não nativas que formam populações numerosas e abundantes e se reproduzem sem intervenção humana direta, causando graves prejuízos ambientais e/ou económicos. As invasoras mais problemáticas são de origem asiática, como a cana e a árvore-do-céu (Ailanthus altissima) ou australianas como a mimosa (Acacia dealbata) e outras acácias, que levam frequentemente ao declínio ou mesmo à extinção local das populações nativas. Estas 
espécies foram provavelmente introduzidas pelo seu valor ornamental ou para sustentação das margens, enquanto outras espécies foram introduzidas como forrageiras, como é o caso do graminhão e rapidamente colonizaram as margens dos rios um pouco por todo o país. Outras espécies causam elevados prejuízos, mas estão ainda circunscritas, como é o caso do piteirão (Eryngium pandanifolium), espécie originária da América do Sul, que invade sobretudo o curso principal do rio Mondego e alguns dos seus tributários (Figura 6.6a). Quanto às espécies aquáticas, a maioria das introduções foi acidental ou pelo valor ornamental das espécies, destacando-se as espécies flutuantes como o jacinto-aquático (Eichbornia crassipes) (Figura 6.6b) e a azola (Azolla spp.) ou a pinheirinha-de-água (Myriophyllum aquaticum) (Figura 6.6c), esta última bem conhecida dos aquariofilistas. Estas espécies estão presentes em várias reservas naturais do país atravessadas por rios ou em zonas húmidas como os pauis (caso do Paul de Boquilobo) e açudes (caso do Açude da Agolada), e sendo muitas vezes designadas por infestantes ambientais, dados os elevados prejuízos no decréscimo de biodiversidade, afetando plantas nativas, peixes e invertebrados e de um modo geral, prejudicando o funcionamento dos ecossistemas ${ }^{13}$.

Entre as principais causas apontadas para estes movimentos invasores, inclui-se a disponibilização de nutrientes provenientes de fontes pontuais e difusas, e as alterações ao regime de caudais, para além de intervenções desadequadas nos perfis naturais dos sistemas fluviais. Portugal foi pioneiro dentro da Europa Comunitária na legislação de espécies exóticas (Decreto-Lei n565/99, de 21 de Dezembro), sendo um dos primeiros países da União Europeia a listar plantas exóticas e invasoras a nível nacional. O Regulamento (UE) $n^{\circ} 1143 / 2014$ elenca catorze espécies de plantas exóticas invasoras que suscitam preocupação ("lista da União"), entre as quais se encontram várias espécies aquáticas que já invadem o nosso país, nomeadamente o jacinto-aquático e a pinheirinha-de-água e outras 
que causam preocupação pelos elevados prejuízos que têm provocado noutros países europeus, como são exemplo as espécies Hydrocotyle ranunculoides, Lagarosiphon major e Cabomba caroliniana.
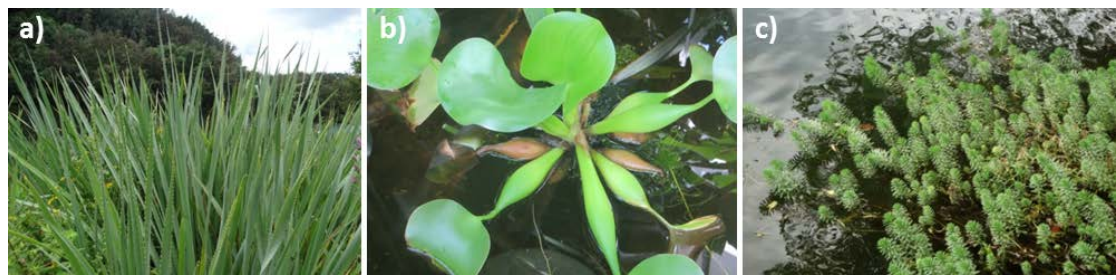

Figura 6.6. Exemplos de plantas exóticas invasoras em rios Portugueses: a) piteirão Eryngium pandanifolium; b) jacinto-aquático Eichbornia crassipes; c) pinheirinha-de-água Myriophylum aquaticum. Fotografias: Francisca Aguiar e Maria Dalila Espírito-Santo.

\section{Habitats e espécies protegidas e sua conservação}

A Diretiva Habitats ${ }^{2}$ transposta para a legislação portuguesa pelo Decreto-Lei n. ${ }^{\circ}$ 49/2005, tendo em consideração a interpretação proposta pela Comissão Europeia, EC (2007), inclui 88 tipos de habitats naturais. Desses habitats há 52 que se podem encontrar associados a sistemas ripícolas e estão representados nos Parques Naturais e Sítios da Rede Natura 2000 (criados ao abrigo das Resoluções de Conselho de Ministros n. ${ }^{\circ}$ 142/97, de 28 de Agosto, e ${ }^{\circ} 76 / 2000$, de 5 de Julho), que incluem os rios Minho, Lima, Sabor e Maçãs, Douro, Paiva, Vouga, Tejo, Sado e Guadiana e as Rias Formosa/ Castro Marim e Alvor.

As galerias ribeirinhas que definem as margens dos rios distribuem-se por cinco tipos de habitats conforme a espécie dominante: (i) freixiais termófilos de Fraxinus angustifolia, (ii) florestas de Alnus glutinosa, (iii) florestas mistas de Quercus robur, Ulmus minor e Fraxinus angustifolia das margens de grandes rios, (iv) 
florestas-galerias de Salix alba e Populus alba e (v) galerias e matos ribeirinhos meridionais com Nerium oleander ou Flueggea tinctoria ${ }^{14}$. Há situações em que não há condições para o desenvolvimento da típica galeria ripícola como acontece nas vertentes rochosas do Sabor onde se dá a ocorrência de formações estáveis de buxo (Buxus sempervirens), onde também ocorrem matagais arborescentes de Juniperus spp. como acontece no Douro Internacional e no Guadiana.

Um tipo diferente de habitat é o que se desenvolve em cursos de escoamento lento com águas mais ou menos ricas em nutrientes e com pouco oxigénio, com comunidades vasculares flutuantes à superfície ou submersas, enraizadas ou suspensas entre o fundo e a superfície, onde são dominantes espécies dos géneros Azolla, Lemna, Hydrocharis, Myriophyllum, Najas, Nymphaea, Nuphar e Potamogetom. Menos frequentes são os charcos temporários mediterrânicos, um tipo de habitat prioritário para a conservação, formados por vezes nas depressões das margens dos rios, sazonalmente inundadas por uma pequena altura de água doce, onde se formam complexos de vegetação anual, anfíbia e efémera, de floração primaveril e de elevada diversidade ${ }^{15,16}$; os pteridófitos (fetos) do género Isoetes que aqui ocorrem podem ser indicadores do tempo de submersão a que esteve sujeito o local. Os habitats naturais formados pelos cursos de água mediterrânicos permanentes com Glaucium flavum, cursos de água dos pisos basal a montano com ranúnculos aquáticos, cursos de água de margens vasosas com Glinus lotoides, cursos de água mediterrânicos permanentes com galerias de salgueiros e choupo-branco e cursos de água mediterrânicos intermitentes com graminhão, podem ser vistos nos rios de norte a sul do país. Também as pradarias húmidas mediterrânicas de ervas altas com Molinia e Scirpoides holoschoenus ${ }^{17}$, as comunidades de ervas altas higrófilas das orlas basais e dos pisos montano a alpino, os prados de feno pobres de baixa altitude e os graminhais perenes e anuais desenvolvidos no período de estiagem, são frequentes nas margens do Minho ao Guadiana. 
O troço final de um rio sujeito ao fluxo das marés, designado frequentemente por sistema estuarino, compreende áreas desprovidas de vegetação vascular e comunidades de plantas vasculares adaptadas ao meio salino. As lagunas costeiras que ao longo do litoral vão aparecendo, resultantes do encerramento da abertura de comunicação com o mar ou de pequenas depressões localizadas no fim de linhas de água temporárias ou permanentes com débitos muito irregulares que não transportam volumes de água suficientes para manter a barra aberta e impedir o seu completo assoreamento, são dos habitats com maior interesse para conservação dentro do sistema estuarino. Conforme o grau de salinidade da laguna encontram-se nela comunidades de plantas aquáticas tais como Najas spp., Potamogeton spp. e Callitriche spp., com caniçais de Phragmites australis, Carex paniculata subsp. lusitanica e Bolboschoenus maritimus var. maritimus, e margens ocupadas por canaviais de Arundo donax, tamargais de Tamarix africana, prados de gramíneas tolerantes ao sal com ou sem Juncus maritimus ou juncais de Juncus acutus.

No Plano Sectorial da Rede Natura 2000 (Diário da República, $1 .^{a}$ série - N. ${ }^{\circ} 139$ - 21 de Julho de 2008) para cada área da Rede Nacional de Áreas Protegidas é realizada uma caracterização exaustiva dos valores naturais (habitats prioritários e espécies prioritárias) e das atividades humanas existentes na área, bem como elencadas as medidas de gestão consideradas pertinentes para a sua conservação. Por seu lado, as fichas oficiais destas espécies contêm, entre outras informações, o estado de conservação, o estatuto de ameaça e a distribuição geral bem como orientações de gestão de atividades humanas e biótopos, para conservação de cada espécie (http://www. icnf.pt/). Porém, mapas georreferenciados das áreas de ocupação das espécies de valor conservacionista não existem para a generalidade dos casos, e concretamente para as espécies dependentes de águas interiores. O Relatório do Estado do Ambiente mais recente 
(2016) reporta $10 \%$ de habitats prioritários em estado mau, $50 \%$ em estado desfavorável e apenas $40 \%$ em estado adequado para a última avaliação realizada em 2012.

Tradicionalmente, o repositório de espécies vegetais era realizado nos vários Herbários nacionais, dos quais os mais importantes são o da Universidade de Coimbra e o da Universidade de Lisboa, incluindo coleções tropicais. Para além do apoio a estudos florísticos de índole vária, estes Herbários exerceram funções importantes de salvaguarda da biodiversidade florística. Em paralelo, eram guardados repositórios de sementes com objetivo de manutenção de património e diversidade genéticos. Com a expansão da genética molecular e genómica, a área da taxonomia e conservação da biodiversidade florística encontra-se em grande mudança, com a possibilidade de observar o passado filogenético, garantir a manutenção da diversidade associada a populações específicas e de certa forma, conduzir o futuro das espécies e comunidades vegetais.

\section{Gestão da vegetação aquática}

Os ecossistemas aquáticos e ribeirinhos das regiões mediterrânicas estão sujeitos a múltiplas perturbações naturais e humanas. A sazonalidade do regime de caudais e as variações intra-anuais de precipitação, típicas de regiões de clima mediterrânico traduzem-se a nível biológico e comunitário, em adaptações das comunidades a estas condições particulares. No entanto, a perturbação humana nas suas múltiplas vertentes e o número crescente de fenómenos extremos como cheias e secas expressam-se numa menor capacidade de adaptação e absorção das perturbações e numa menor resiliência. As maiores perturbações humanas estão sobretudo relacionadas com os efeitos da ocupação do solo nas áreas adjacentes e com alterações no regime hidrológico, devido a captações de água subterrânea e 
à regularização de caudais ${ }^{18}$. Outras alterações correntes incluem a alteração dos perfis transversais e longitudinais, e a destruição da vegetação ripária e habitats do leito, por exemplo, por zonas de bebedouro de gado, rede viária e ferroviária e estradas locais (Figura 6.7).

A necessidade de dar resposta institucional à DQA e o esforço da sua implementação a nível nacional e na UE permitiu constituir a primeira base de dados florísticos e fisico-químicos estandardizada a nível nacional (APA IP, 2004-2005). Este investimento em dados de base impulsionou o desenvolvimento de índices com vista à gestão e monitorização das massas de água ${ }^{19,20}$. Em particular, a intercalibração da qualidade biológica de rios do Grupo Geográfico Mediterrânico de Macrófitos (Portugal, Espanha, França, Itália, Grécia, Eslovénia, Chipre) permitiu a identificação de espécies bioindicadoras (espécies que respondem de forma consistente e coerente à perturbação) e a validação de um índice normativo para Portugal ${ }^{21}$, o Índice Biológico de Macrófitos de Rio (IBMR) ${ }^{22}$, baseado em espécies indicadoras herbáceas (Capítulo 14). Este índice é regularmente utilizado na monitorização de massas de águas interiores, podendo ser calculado em http://www.isa.ulisboa.pt/proj/ibmr/.
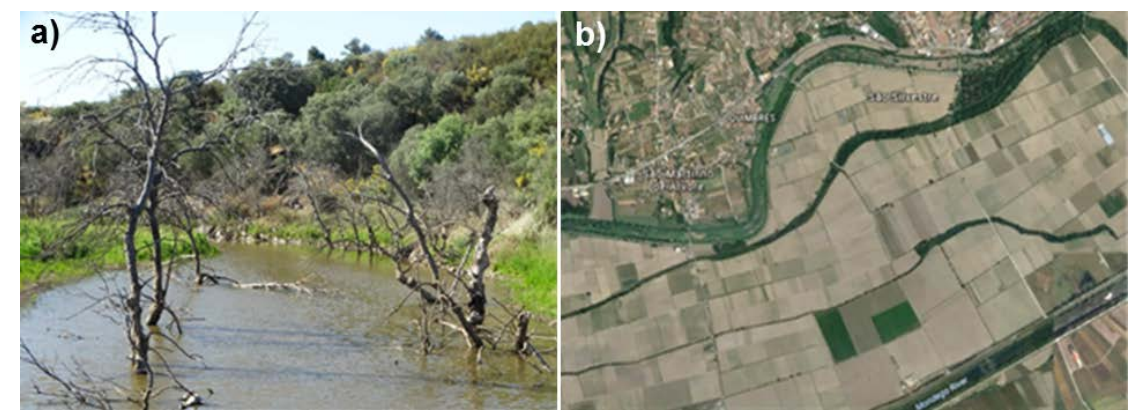

Figura 6.7. a) Asfixia do freixial na Ribeira da Asseca, na zona de influência da albufeira do Alqueva; b) linearização do perfil longitudinal com isolamento de meandro original no rio Mondego. Fotografias:

Francisca Aguiar e Image-DigitalGlobe - Google Earth ${ }^{\mathrm{tm}} 2016$. 
O IBMR está particularmente vocacionado para detetar poluição nutritiva e orgânica. Em sistemas mediterrâneos, sujeitos a grandes variações anuais de caudal, será mais consequente ter em conta toda a comunidade que habita o corredor fluvial, incluindo espécies terrestres e lenhosas, pois a sua proporção permite verificar a resposta a outras formas de alterações, por exemplo o número e cobertura em hidrófitos responde à diminuição de caudais estivais. No âmbito da DQA, foi desenvolvido o Índice de Vegetação Ripária ${ }^{19}$, baseado em parâmetros passíveis de quantificação relacionados com a composição florística, estruturais e funcionais e incluindo toda a vegetação existente.

Os índices desenvolvidos têm sido utilizados em conjunto ou isoladamente para avaliação e monitorização da qualidade ecológica, permitindo classificar as massas de água em Excelente, Bom, Razoável, Medíocre e Mau. As massas de água com classificação do índice normativo inferior a Bom deverão ser sujeitas a ações de requalificação de modo a atingir o estado de qualidade Bom.

As comunidades ribeirinhas ibéricas têm uma importância desproporcionada em relação à pequena área que ocupam, sendo essencial a sua conservação, gestão ou requalificação/restauro. O restauro destes ecossistemas é um processo complexo que envolve a integração e conhecimento de um vasto conjunto de processos hidrológicos, geomorfológicos, edáficos, microclimáticos e biológicos ${ }^{23}$. Grande parte do processo de restauro ecológico passa por retirar ou reverter as pressões exercidas pelas atividades humanas - enriquecimento nutritivo, pisoteio, depósitos de lixo, cortes rasos indiscriminados, alterações e artificializações dos perfis longitudinais e transversais dos leitos, alteração do regime natural de caudais. Na maior parte dos casos esta retirada de pressões deve ser acompanhada da reconstituição hidrogeomorfológica do ecossistema, que pode ocorrer quer por intervenção direta com obras de engenharia fluvial (p.ex., controlo de erosão de margens e consolidação destas, criação de bacias de sedimentação, controlo de espécies exóticas invasoras ou renaturalização 
de meandros). Finalmente, para uma parte dos casos é necessário a reconstituição da própria galeria ribeirinha, através da plantação de árvores ripárias e proteção do seu desenvolvimento (Figura 6.8).

Para esta reconstituição é necessário conhecer a galeria ribeirinha que naturalmente estaria associada ao tipo de rio $^{24}$. Nos últimos anos, a instrumentação estatística e geoestatística começam a permitir relacionar o modelado geográfico com as características ecológicas de cada espécie, permitindo o mapeamento da probabilidade de ocorrência e mesmo área das espécies, nomeadamente ripárias. O projeto RIPLANTE, por exemplo, permite encontrar a distribuição probabilística das oito espécies lenhosas mais comuns em Portugal (amieiro, freixo, tamujo, sanguinho-de-água, loendro, borrazeira-negra, borrazeira-branca e tamargueira) a uma escala de 1:25000 (http://riplante.apambiente.pt/ riplante/). O site encontra-se dotado de um sistema de informação, permitindo a consulta de mapas em formato raster com a probabilidade de ocorrência das espécies representada de forma contínua ao longo da rede hidrográfica do continente português, mapas vetoriais com a representação das áreas ambientalmente homogéneas onde as diferentes espécies se desenvolvem e a localização de populações conhecidas das espécies lenhosas ribeirinhas.
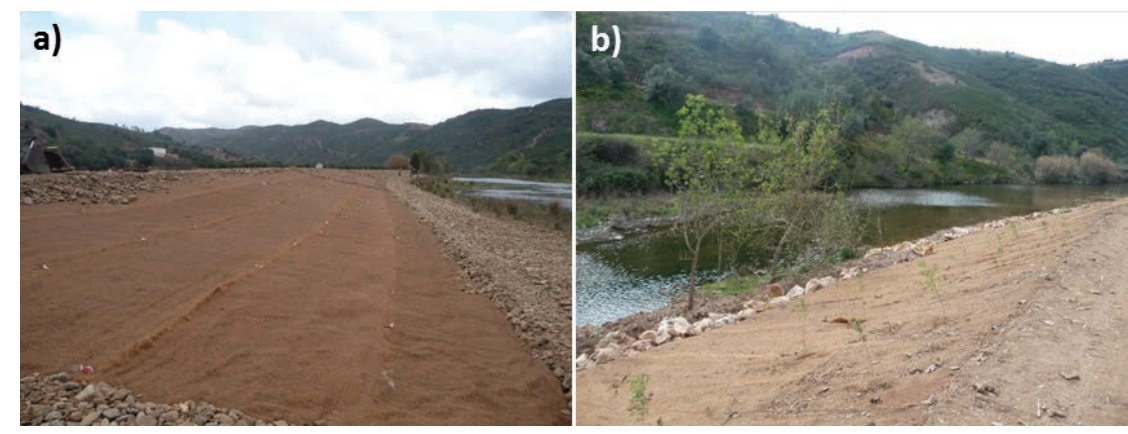

Figura 6.8. Reconstituição da galeria ribeirinha na ribeira de Odelouca: a) estabilização do solo da margem com geotêxtil antes da reconstituição; b) colocação das plantas junto da margem e na zona de estabilização. Fotografias: Teresa Ferreira e Rui Cortes 
Este tipo de ferramentas é um auxiliar precioso nas ações de conservação e reconstituição de galerias ribeirinhas, juntamente com a definição das adequadas técnicas de propagação e instalação das árvores e arbustos jovens. Noutros casos, recorre-se igualmente ao reforço de populações vegetais naturais ameaçadas através de plantio ou sementeira.

Os grandes avanços no conhecimento dos efeitos das pressões humanas sobre os ecossistemas fluviais, o desenvolvimento de instrumentos poderosos de imagem remota e de genómica, a crescente disponibilização de informação, e o reconhecimento da necessidade de abordagens multidisciplinares, abrangentes e transnacionais irão marcar a evolução da gestão da vegetação fluvial ${ }^{25}$. Desejavelmente estes instrumentos e avanços terão aplicação prática na gestão e restauro de ecossistemas fluviais e concretamente da sua vegetação, por exemplo, com a deteção remota de invasões por espécies exóticas e planeamento do seu controlo, monitorização e priorização de locais para restauro, reconstituição de galerias ribeirinhas. Por outro lado, têm surgido novos modelos conceptuais baseados nos processos funcionais dos ecossistemas e no potencial preditivo de grupos funcionais, apelando ao processamento de bancos de dados extensos.

Entre as prioridades de investigação nesta área, incluem-se estudos das trajetórias de evolução genética, morfológica e funcional de adaptação às alterações climáticas de plantas ribeirinhas e aquáticas. Uma outra linha prioritária de investigação diz respeito à configuração espacial e estrutural ótima dos bosques ribeirinhos para a sustentabilidade das comunidades biológicas e manutenção de processos dos ecossistemas, com importantes implicações para o restauro destas comunidades degradadas. Por outro lado, é necessário aprofundar o conhecimento do funcionamento de infraestruturas verdes e azuis (sobretudo em ambiente urbano) nas suas interações entre ecologia, hidrologia e provisão de serviços dos ecossistemas, bem como da suscetibilidade dos ecossistemas fluviais a invasões 
biológicas, e sua relação com a dinâmica dos recursos habitacionais existentes (p.ex., picos hidrológicos e de nutrientes).

\section{Outras leituras}

Aguiar F.C. 2011. Galerias ribeirinhas Mediterrânicas - Oasis lineares. http://naturlink. $\mathrm{pt} /$ article .aspx menuid $=4 \& \mathrm{cid}=94227 \& \mathrm{bl}=1$

Aguiar F.C., Fabião A.M., Bejarano M.D., Merritt D., Nilsson C., Martins M.J. 2013. FLOWBASE - a riparian plant traitbase (http://www.isa.ulisboa.pt/proj/flowbase/). Centro de Estudos Florestais, Instituto Superior de Agronomia, Universidade de Lisboa, Lisboa, Portugal.

Campodron J., Ferreira M.T., Ordeix M. (eds). Restauro e gestão ecológica fluvial. Manual de boas práticas e gestão de rios e ribeiras. Interreg IVC SUDOE Ricover. CTFC/ISAPress, Solsona

Flora-On: Flora de Portugal Interactiva. 2014. Sociedade Portuguesa de Botânica. (www.flora-on.pt)

Malanson G.P. 1993. Riparian landscapes. Cambridge University Press. UK. Cambridge,

Naiman R.J., Décamps H. \& McClain M.E. 2005. Riparia: ecology, conservation, and management of streamside communities. Elsevier Academic Press. USA, San Diego

Plantas invasoras em Portugal: http://invasoras.pt

Keddy P.A. 2000. Wetland ecology: principles and conservation. Cambridge University Press. UK, Cambridge

\section{Referências bibliográficas}

${ }^{1}$ Costa J.C., Aguiar C., Capelo J.H., Lousã M. \& Neto C. 1998. Biogeografia de Portugal continental. Quercetea, $46 \mathrm{pp}$

2 Comissão Europeia. 1992. Directiva 92/43/CEE do Concelho de 21 de Maio de 1992 relativa à preservação dos habitats naturais e da fauna e da flora selvagens. J. Oficial Com. Europeias L206: 7-50

3 Comissão Europeia. 2000. Directiva 2000/60/CE do Parlamento Europeu e do Concelho de 23 de Outubro de 2000, que estabelece um Quadro de Acção Comunitária no Domínio da Politica da Água. J. Oficial Com. Europeias L327: 1-72

${ }^{4}$ Ferreira M.T. \& Moreira I. 1999. River plants from an Iberian basin and environmental factors influencing their distribution. Hydrobiologia 415: 101-107

${ }^{5}$ Ferreira M.T., Aguiar F. \& Moreira I. 2004. Macrófitos fluviais. Padrões espaciais de distribuição e factores ambientais determinantes. In: Moreira I., Saraiva M.G., Nunes Correia F. (eds.), Gestão ambiental dos sistemas fluviais. Aplicação à bacia bidrográfica do rio Sado. ISA Press. Portugal, Lisboa, pp. 247-264 
${ }^{6}$ Sérgio C., Garcia C.A., Sim-Sim M., Vieira C., Hespanhol H. \& Stow S. 2013. Atlas e livro vermelho dos briófitos ameaçados de Portugal. Museu Nacional de História Natural e da Ciência. Portugal, Lisboa

${ }^{7}$ Vieira C., Aguiar F.C. \& Ferreira M.T. 2014. The relevance of bryophytes in the macrophytebased reference conditions in Portuguese rivers. Hydrobiologia 737: 245-264

${ }^{8}$ Ribeiro J.A. 2000. Flora e vegetação ribeirinha. Douro-Estudos \& Documentos 9: 39-45

${ }^{9}$ Duarte M.C. \& Moreira I. 2009. Flora aquática e ribeirinha. Administração da Região Hidrográfica do Algarve I.P. Portugal, Faro

${ }^{10}$ Aguiar F., Costa J.C., Duarte M.C., Fabião A.D., Ferreira M.T., Ramos I.L., Lousã M. \& Monteiro F.P. (autores), I. Moreira \& G. Saraiva (coordenadores). 1999. As galerias ribeirinhas na paisagem mediterrânica: reconhecimento na bacia bidrográfica do rio Sado. ISA Press. Portugal, Lisboa

${ }^{11}$ Corenblit D., Davies N.S., Steiger J., Gibling M.R. \& Bornette G. 2015. Considering river structure and stability in the light of evolution: feedbacks between riparian vegetation and hydrogeomorphology. Earth Surf. Process. Landf. 40: 189-207

${ }^{12}$ Aguiar F.C.F. \& Ferreira M.T. 2013. Plant invasions in the rivers of the Iberian Peninsula, South-Western Europe - a review. Plant Biosyst. 147: 1107-1119

13Moreira I., Ferreira M.T., Monteiro A., Catarino L.F. \& Vasconcelos T. 1999. Aquatic weeds and their management in Portugal: insights and the international context. Hydrobiologia 415: 229-234

${ }^{14}$ Aguiar C., Capelo J., Costa J.C., Espírito-Santo M.D. \& Lousã M. 1995. Tipologia das geosséries ripícolas mediterrânicas de Portugal continental. $3^{\circ}$ Congresso Nacional Conservação da Natureza: 25-32

${ }^{15}$ Pinto-Cruz C., Molina J.A., Barbour M., Silva V. \& Espírito-Santo M.D. 2009. Plant communities as a tool in temporary ponds conservation in SW Portugal. Hydrobiologia 634: 11-24

${ }^{16}$ Pinto-Cruz C., Barbosa A.M., Molina J.A. \& Espírito-Santo M.D. 2011. Temporary ponds in Mediterranean Ecosystems: biotic and abiotic factors that distinguish pond types. Ecol. Ind. 11: 1658-1663

${ }^{17}$ Ribeiro S., Ladero M. \& Espírito-Santo M.D. 2013. Patterns of floristic composition of Mediterranean meadows and mesophytic grasslands in eastern Continental Portugal. Plant Biosyst. 147: 874-892

${ }^{18}$ Ferreira M.T.\& Moreira I. 2002. Ecologia e gestão de ecossistemas dulçaquícolas. In: I. Moreira, M.T. Ferreira, R. Cortes, P. Pinto \& P.R. Almeida (eds). Ecossistemas aquáticos e ribeirinhos. Ecologia, gestão e conservação 1.3-1.13. Instituto da Água. Portugal, Lisboa

${ }^{19}$ Aguiar F.C., Ferreira M.T., Albuquerque A., Rodríguez-González P. \& Segurado P. 2009. Structural and functional responses of riparian vegetation to human disturbance: performance and spatial-scale dependence. Fund. Appl. Limnol. 175: 249-267

${ }^{20}$ Aguiar F.C., Feio M.J. \& Ferreira M.T. 2011. Choosing the best method for stream bioassessment using macrophyte communities: indices and predictive models. Ecol. Ind. 11: 379-388

${ }^{21}$ Aguiar F.C., Segurado P., Urbanic G, Cambra J., Chauvin C., Ciadamidaro S., Dörflinger G., Ferreira J., Germ M., Manolaki P., Minciardi M.R., Munné A., Papastergiadou 
E. \& Ferreira M.T. 2014. Comparability of river quality assessment using macrophytes: a multi-step procedure to overcome biogeographical differences. Sci. Total Environ. 476-477: 757-767

${ }^{22}$ Haury J., Peltre M.-C., Trémolières M., Barbe J., Thiébaut G., Bernez I., Daniel H., Chatenet P., Haan-Archipof G., Muller S. \& Dutartre A. 2006. A new method for assess water trophy and organic pollution - the Macrophyte Biological Index for Rivers (IBMR): its application to different types of rivers and pollution. Hydrobiologia 570: 153-58

${ }^{23}$ González E., Felipe-Lucia M.R., Bourgeois B., Boz B., Nilsson C., Palmer G., Sher A.A. 2017. Integrative conservation of riparian zones. Biol. Conserv. 211: 20-29

${ }^{24}$ Aguiar F.C., Cerdeira J.O., Martins M.J. \& Ferreira M.T. 2013. Riparian forests of Southwest Europe: are functional trait and species composition assemblages constrained by environment? J. Veg. Sci. 24: 628-638

${ }^{25}$ O'Hare M.T., Aguiar F.C., Asaeda T., Bakker E.S., Chambers P.A., Clayton J.S., Elger A., Ferreira T.M., Gross E.M., Gunn I.D.M., Gurnell A.M., Hellsten S., Hofstra D.E., Li W., Mohr S., Puijalon S., Szoszkiewicz K., Willby N.J. \& Wood K.A. 2018. Plants in aquatic ecosystems: current trends and future directions. Hydrobiologia 812: 1-11 